\title{
An experimental study on drilling of titanium alloy using $\mathrm{CO}_{2}$ laser
}

\author{
SUMAN CHATTERJEE ${ }^{1}$, SIBA SANKAR MAHAPATRA ${ }^{1, *}$, ARPAN MONDAL $^{2}$ and \\ KUMAR ABHISHEK ${ }^{3}$
}

${ }^{1}$ Department of Mechanical Engineering, National Institute of Technology Rourkela, Rourkela 769008, India

${ }^{2}$ National Institute of Technical Teachers' Training and Research, Kolkata 700106, India

${ }^{3}$ Department of Mechanical Engineering, Institute of Infrastructure, Technology, Research and Management, Ahmedabad 380026, India

e-mail: mrsumanmech@gmail.com; mahapatrass2003@gmail.com; arpan.nitttrk@gmail.com;

krabhishek1987@gmail.com

MS received 16 March 2016; revised 7 January 2017; accepted 16 April 2018; published online 3 July 2018

\begin{abstract}
Laser drilling is a popular method as it eliminates the problem of chatter and vibration due to the absence of physical contact between the tool and workpiece. Tool breakage, a common phenomenon that occurs due to bending of the tool in making of slender holes using conventional drilling, can also be avoided. However, quality of the hole measured in terms of circularity, taper and spatter area is the major concern during laser drilling. The present investigation attempts to find out the optimum parametric setting during drilling of Ti6Al4V using $\mathrm{CO}_{2}$ laser in order to achieve quality holes. Experiments have been conducted to assess the influence of machining parameters, viz. flushing pressure, laser power and pulse frequency, on the performance characteristics such as taper of kerf, heat-affected zone (HAZ) and spatter area. Taguchi's $\mathrm{L}_{9}$ orthogonal array has been used to design the experimental layout as it reduces the experimental cost and time. Analysis of variance has been performed to assess the effect of machining parameter on the performance characteristics. It has been observed that laser power has significant influence on taper of kerf, HAZ and spatter area. Based on desirability approach, the study suggests that all the performance characteristics can be simultaneously optimized at flushing pressure of $40 \mathrm{~Pa}$, laser power of $2250 \mathrm{~W}$ and pulse frequency of $1600 \mathrm{~Hz}$. The study also presents a numerical model to simulate the laser drilling process. Since comparison of experimental and numerical model shows a relative error within $10 \%$, adequacy of the numerical model for assessment of quality characteristics of laser drilled holes is justified.
\end{abstract}

Keywords. $\quad \mathrm{CO}_{2}$ laser; desirability function (DF); heat-affected zone (HAZ); spatter area; taper.

\section{Introduction}

Titanium alloy (Ti6Al4V), a combination of alpha-beta alloy having chemical composition of $6 \%$ aluminium, $4 \%$ vanadium and remaining titanium, is widely used for most of the daily appliances as well as bio-medical applications due to bio-compatibility. Small holes (micro-drilling) in the range of a few hundred microns with high aspect ratio are generally required in biomedical, aerospace and electronic applications. Drilling of such alloys sometimes poses difficulty because the material is work hardened and the tool rubs against the hardened zone, causing rapid tool wear $[1,2]$. Moreover, drill bits in micro-drilling frequently bend due to their slender shape [3]. The aforementioned difficulties adversely affect the quality of holes characterized in terms of burr formation, taper, lack of circularity and high surface roughness. In order to alleviate these problems,

*For correspondence micro-drilling through the use of laser is preferred since no contact between tool and the work material is required in laser drilling eliminating the problems of chatter and vibration [4]. Laser machining is considered as a sustainable alternative for micro-drilling of metals, composites, ceramics and polymers. The standard lasers used for the laser machining process are ruby laser, Nd:YAG (Neodymium Yttrium Aluminium Garnet) and carbon dioxide $\left(\mathrm{CO}_{2}\right)$ gas. In laser drilling operation, a high-energy infrared laser beam is focused on a spot on the workpiece varying between 0.1 and $2.0 \mathrm{~mm}$ in diameter resulting in melting, vaporization and chemical degradation throughout the depth of the material. Deep holes with small diameters can be drilled with little thermal or mechanical damage to the material. Literature suggests that laser drilling is an alternative for attaining good quality micro-holes [4-8]. Several process-related parameters generally influence the quality of holes. The quality of the hole can be improved if spatter deposition, taper of the kerf and heat-affected zone 
(HAZ) are minimized and circularity is enhanced in laser drilling process.

Low et al [5] have studied the spatter deposition during laser drilling of Nimonic 263 alloy using a fibreoptic-delivered 400-W Nd:YAG laser. Ghoreishi et al [6] have investigated the influence of control variables on hole taper and circularity in laser percussion drilling using stainless steel as workpiece. Brajdic et al [7] have investigated the effect of laser drilling parameters on hole quality in deep drilling of through holes made on stainless steel with the superposed radiation of two pulsed Nd:YAG lasers. Nagesh et al [8] have directed their efforts in improving the quality of laser-drilled holes in thermoset-based composites. The results indicate that the HAZ can be reduced by employing low laser power whereas taper angle can be reduced by adopting high laser power. Shelton and Shin [9] have used $\mathrm{CO}_{2}$ laser while machining various materials such as AISI 422, AISI 316, Inconel 718 and Ti6Al4V to study the effect of process parameters on the machining performance characteristics such as workpiece micro-structure, edge burrs and surface finish. Yan et al [10] have used a $\mathrm{CO}_{2}$ laser for drilling of thick aluminium sheets with a view to minimize hole taper and spatter area. Since laser machining is an expensive process, requirement of systematic experimental layout that can be attained by design of experiment (DOE) approach has been realized to reduce the experimental cost and time. El-Taweel et al [11] have proposed a Taguchi method for laser drilling of Kevlar-49 using $\mathrm{CO}_{2}$ laser. Implementation of Taguchi method helps in systematically analysing the effect of process parameters on quality of laser-drilled hole such as taper, kerf width and dross height. Shuja and Yilbas [12] have employed $\mathrm{CO}_{2}$ laser for drilling of coated carbon steel material to study the effect of assisting gas on the quality of drilled holes surface. In addition to experimental investigations, several numerical studies based on finite-element method (FEM) have been suggested to conduct numerical analysis on laser machining process to analyse the thermal and mechanical behaviour of the materials. Models have been proposed to predict the heat transfer rate during laser-assisted machining of silicon nitride [13-15]. Tsai and Chen [16] have successfully developed a finite-element (FE) model to analyse the mechanism of laser-controlled machining. Yan et al [10] have proposed numerical models to estimate the performance characteristics during $\mathrm{CO}_{2}$ laser drilling of alumina ceramics. Bharatish et al [17] have developed a numerical model to estimate radial distance from the centre of machining.

Extensive literature review reveals that few attempts have been made on micro-drilling of Ti6Al4V using laser and use of $\mathrm{CO}_{2}$ laser to machine metallic alloys. However, $\mathrm{CO}_{2}$ laser is preferable for drilling of composites and plastic materials [1,8-11, 17-21]. Some studies have used $\mathrm{CO}_{2}$ laser for drilling of alloys such as alumina and aluminium composites [10-12]. Titanium alloy of grade5 (Ti6Al4V) contains aluminium in its constituents. The presence of aluminium in its constituents makes $\mathrm{CO}_{2}$ laser suitable for machining of $\mathrm{Ti} 6 \mathrm{Al} 4 \mathrm{~V}$. The present study attempts to address the applicability of $\mathrm{CO}_{2}$ laser in drilling of metallic alloys and effectiveness of $\mathrm{CO}_{2}$ laser on drilling of titanium alloys of thin sheet $(2 \mathrm{~mm}$ thickness). The influence of input process parameters such as flushing pressure (nitrogen gas), laser power and pulse frequency on performance characteristics like taper of the kerf, spatter area and HAZ using the Taguchi method has been studied. The rationale in using Taguchi method lies in the fact that the method extracts maximum information with less number of experimental runs. An FE model is proposed to estimate HAZ and taper of the kerf during laser drilling. The results from numerical model is compared to experimental results. In order to optimize multiple performance characteristics simultaneously, the performance characteristics are converted into single-performance characteristic using desirability function approach (DFA). Optimal setting for multiple performance characteristics is judged from factorial plots obtained by Taguchi method.

\section{Desirability Function Approach (DFA)}

DFA was proposed by Derringer [22] in early 1980. Due to non-complicated mathematical formulation and computational easiness [22-25], DFA is widely adopted as an optimization technique for optimization of multiple performance characteristics simultaneously. It normally converts the multiple performance characteristics into a singleequivalent characteristic in the form of overall desirability value. In DFA, each performance characteristic is converted into corresponding desirability values [25-30]. The desirability values are contingent to define tolerance limits along with target of the response. In DFA, the desirability value depends on acceptable tolerance range as well as target of the response. Unity is assigned as the response reaches its target value, which is the most desired situation. If the value of the response falls beyond the prescribed tolerance range, which is not desired, its desirability value is assumed to be zero. Therefore, desirability value may vary from zero to unity. The desirability values are aggregated together to obtain the overall desirability value, which is further converted into signal to noise $(\mathrm{S} / \mathrm{N})$ ratio. As the $\log$ value of unity is zero and $\log$ of zero is undefined, desirability values are varied between 0.5 and 0.9 instead of $0-1$ in the study. If the characteristic value satisfies its defined target value, desirability value is assigned 0.9. If the response fails to satisfy its defined target range, it is considered to be a non-desired value and its desirability value is assigned 0.5 . The individual desirability values for each performance characteristics have been calculated 
using Eqs. (1)-(6) [22-27]. If the required condition is lower-the-better (LTB), the desirability value is obtained using Eqs. (1)-(3) and Eqs. (4)-(6) are used for higher-thebetter (HTB) condition. The individual desirability values of an experimental run are aggregated into overall desirability value using Eq. (7).

\subsection{Lower-the-better (LTB)}

$Y_{i j}$ is considered as the experimental response value for $j^{\text {th }}$ response in $i^{\text {th }}$ trial and $Y_{\min }$ and $Y_{\max }$ are the minimum and maximum experimental response for $j^{\text {th }}$ response. If $Y_{i j}$ value lies below the defined limit, the desirability value $d_{i j}$ is assigned 0.9 (Eq. (1)). If $Y_{i j}$ lies between the limits, the desirability value $d_{i j}$ can be obtained from Eq. (2) and its value lies between 0.5 and 0.9 . If $Y_{i j}$ equals or exceeds the defined limits, desirability value $d_{i j}$ is assigned 0.5 (Eq. (3)). The exponent value (desirability function index) $r$ is assigned 1 [25]. Figure 1 illustrates variation of desirability value with desirability function index for the LTB criterion.

$$
\begin{gathered}
\text { If } Y_{i j} \leq Y_{\min }, d_{i j}=0.9 \\
\text { If } Y_{\min } \leq Y_{i j} \leq Y_{\max }, \quad d_{i j}=\left[\frac{\left(Y_{\max }-Y_{i j}\right)}{\left(Y_{\max }-Y_{\min }\right)}\right]^{r} \\
\text { If } Y_{i j} \geq Y_{\max }, \quad d_{i j}=0.5
\end{gathered}
$$

\subsection{Higher-the-better (HTB)}

When the HTB condition is considered, $d_{i j}$ is assigned 0.9 if $Y_{i j}$ equals or exceeds the defined limits. If $Y_{i j}$ is less than the defined limit, the desirability value $d_{i j}$ is assigned 0.5 . If $Y_{i j}$ lies between the limits, $d_{i j}$ is calculated from Eq. (5) and ranges between 0.5 and 0.9 . Desirability function for the HTB criterion is shown in figure 2.

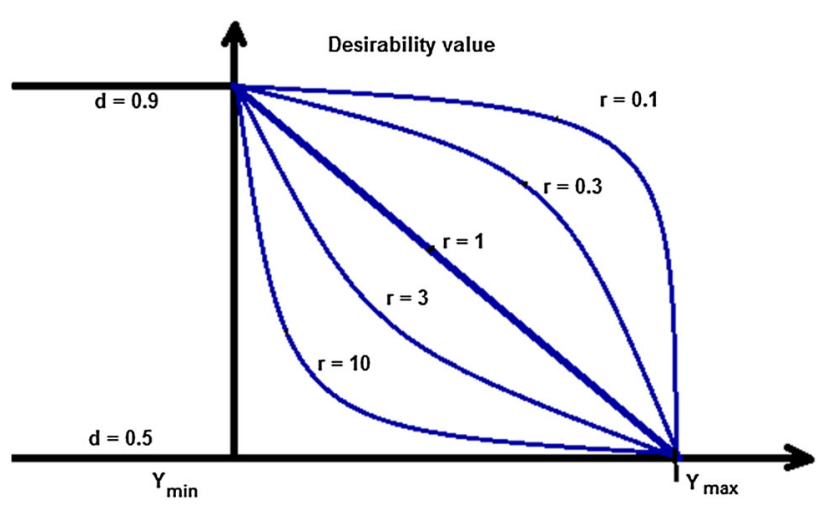

Figure 1. Desirability function curve for lower-the-better (LTB) (which is $r=10$ in the figure).

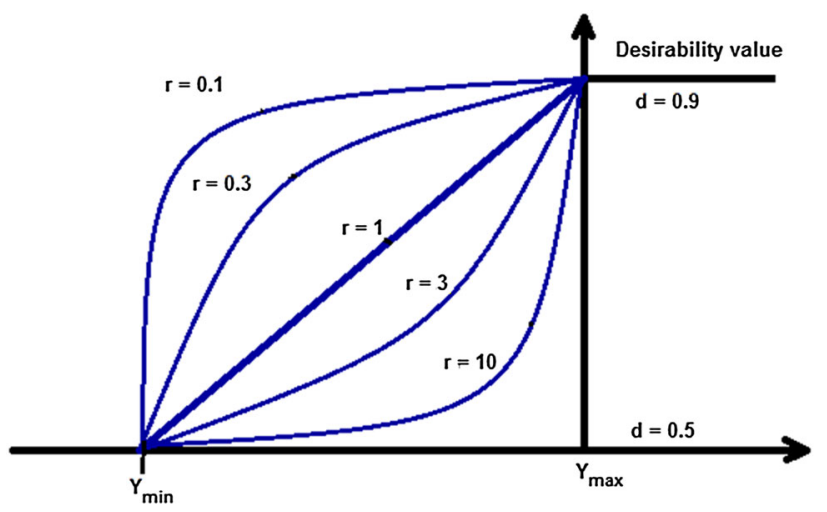

Figure 2. Desirability function curve for higher-the-better (HTB).

$$
\begin{gathered}
\text { If } Y_{i j} \leq Y_{\min }, d_{i j}=0.5 \\
\text { If } Y_{\min } \leq Y_{i j} \leq Y_{\max }, \quad d_{i j}=\left[\frac{\left(Y_{i j}-Y \max \right)}{\left(Y_{\max }-Y_{\min }\right)}\right]^{r} \\
\text { If } Y_{i j} \geq Y_{\max }, \quad d_{i j}=0.9
\end{gathered}
$$

After obtaining the desirability values, each individual desirability values are aggregated together to obtain overall desirability $\left(D_{i 0}\right)$ value using Eq. $(7)$ and $w_{j}$ is the assigned weightage of the performance characteristics (attributes). Sum of weights should be equal to one (Eq. (8)).

$$
\begin{gathered}
D_{i o}=\left(d_{i 1}^{w_{1}} d_{i 2}^{w_{2}} d_{i 3}^{w_{3}} \ldots d_{i n}^{w_{n}}\right)^{\sum^{1} w_{j}} \\
\sum_{j=1}^{n} w_{j}=1 \quad\left(w_{j} \geq 0\right)
\end{gathered}
$$

The overall desirability value is converted into $\mathrm{S} / \mathrm{N}$ ratio using Eq. (9):

$$
S N_{i}=-10 \log _{10}\left[\frac{1}{D_{i o}^{2}}\right]
$$

where $S N_{i}$ is the $\mathrm{S} / \mathrm{N}$ ratio for $i^{\text {th }}$ trial.

\section{Materials and methods}

Lasers are the sustainable alternative used in various aspects of machining processes in manufacturing industries. The major advantage in laser machining is that there is no contact between tool and the work materials, thus eliminating the problem of chatter and vibration during machining of metal and metal alloys [4-6]. Lasers can be efficiently applied in machining of different materials such as metals, composites, ceramics and polymers. Now-adays, micro-laser drilling has emerged as a popular machining process, which is widely applicable in industries, particularly aerospace, automotive and bio-medical 
engineering fields. In laser drilling, a high-energy infrared laser beam (between 0.1 and $2.0 \mathrm{~mm}$ in diameter) is focused on a spot at the workpiece. It may cause melting, vaporization and chemical degradation throughout the depth of the material. The fluids and degraded materials from the holes are removed by assistant gas or gas jet coaxial to the laser beam.

In this present study, experimentation has been carried out on a high-speed laser cutting machine (Orion-3015 $\mathrm{CO}_{2}$ laser cutting machine operating between 100 and $2500 \mathrm{~W}$ ) and the machine is a single-mode laser with continuous wave emitting wavelength of $10 \mu \mathrm{m}$. A machining time of $10 \mu \mathrm{s}$ is considered. The substantial advantage achieved in using lasers for machining lies in the fact that it can machine materials of high strength to weight ratio. It can be used in machining of complex parts and shapes. The current challenge faced by the tool makers needs investigation on effect of laser process parameters such as laser power, pulse frequency and flushing pressure on the performance characteristics like HAZ, taper of the kerf and quality of the surface in laser machining [5, 6]. To meet this challenge, the present study focuses on the details of materials and methods used in laser drilling by theoretical and experimental investigation.

\subsection{Numerical model}

An FE-based numerical model has been proposed for laser drilling of Ti6Al4V to validate the experimental results. A two-dimensional (2D) model axisymmetric with respect to $y$-axis has been considered here. To analyse the model, the 2D model is converted into a 3D model through extrusion

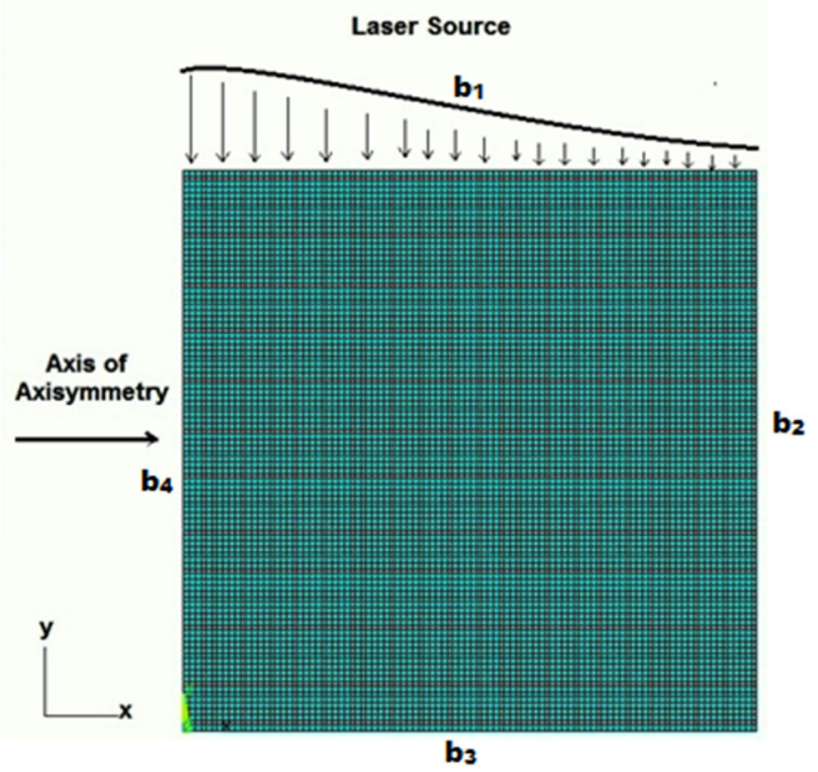

Figure 3. Two-dimensional axisymmetric finite-element model. after analysis. The domain considered is 3 and $2 \mathrm{~mm}$ along $x$ - and $y$-axis, respectively. 2D Axisymmetric-ThermalSolid-Plane 55 (figure 3) has been employed for the transient analysis. The values of the material properties used in the model are enlisted in table 1. For meshing, element size of $1 \mu \mathrm{m}$ is considered for the model in order to enhance the accuracy of the model. The model considered for the analysis closely follows the experimental set-up so that the boundary conditions and dimensions are sufficient for simulating the laser drilling process $[10,15]$. Following are the assumptions made for analysing the laser drilling of Ti6Al4V [10, 15, 31, 32].

a) The material (workpiece) is considered to be opaque and isotropic, and exhibits isotropic heat transfer characteristics.

b) The laser energy distribution of the beam is in Gaussian form at $\mathrm{TEM}_{00}$ mode.

c) With an appropriate depth of focus, the laser energy intensity is equal along the thickness of the workpiece.

d) Initially the entire domain temperature is considered as ambient room temperature.

e) The energy is transferred in the form of heat to the workpiece from the top surface $b_{1}$ (figure 3 ). The boundaries such as $b_{2}$ and $b_{3}$ (figure 3 ) are considered at such a large distance that there is no heat transfer that takes place across them. As the boundary $b_{4}$ (figure 3 ) is an axisymmetric plane, the net heat gain or loss is absolutely zero.

f) The molten material is removed immediately from the workpiece using an assistant gas at a pressure. Thus, no vaporization occurs.

g) The laser-generated reflection within the hole is negligible.

h) Laser beam that acts on the material surface is affected by absorption, reflectivity, transmission and surface roughness of the material. However, for simplification, only absorption and reflectivity of the material are considered.

i) Phase change is neglected due to small fraction of the resolidified region.

j) The cooling effect of the inert gas is neglected.

$\mathrm{CO}_{2}$ laser used for the investigation is considered as the heat generating source, which generates heat flux $Q$ on the irradiated surface of the work model. Therefore, heat flux model for the laser is determined as per Gaussian distribution given by Eq. (10) [10, 15]:

Table 1. Material properties of Ti6Al4V [9].

\begin{tabular}{lcc}
\hline Properties & Units & Values \\
\hline Density & $\mathrm{kg} / \mathrm{m}^{3}$ & 4430 \\
Specific heat & $\mathrm{J} / \mathrm{kg} \mathrm{K}$ & 1.9278 \\
Thermal conductivity & $\mathrm{W} / \mathrm{m} \mathrm{K}$ & 6.7 \\
Melting point & $\mathrm{K}$ & 1873 \\
\hline
\end{tabular}




$$
Q=\frac{2 \alpha P}{\pi R_{s}^{2}} e^{-2\left(R^{2} / R_{s}^{2}\right)}
$$

where $\alpha$ is the absorptivity of the work material, $P$ is the laser power, $R_{\mathrm{S}}$ is the laser spot radius and $R$ is the waist radius of the focused laser beams. The other input process parameters used for the model are enlisted in table 1 . The heat flux is applied on the top surface of the material along $y$-axis.

Heat convection is applied on the surface of the work model as the boundary condition. The convection heat loss is expressed by the following equation [15, 33]:

$$
k(T) \frac{\partial T}{\partial \vec{n}}=-h\left(T-T_{0}\right)
$$

where $k(T)$ is temperature-dependent thermal conductivity (table 1$), \vec{n}$ is a normal vector pointing outward from the free surface, $h$ denotes the heat convection coefficient $\left(200 \mathrm{~W} / \mathrm{m}^{2} \mathrm{~K}\right)$ and $T_{0}$ is the environmental temperature (298 K). The numerical analysis is performed in ANSYS 15. Elements above the melting temperature of workpiece were killed. Finally, the HAZ is calculated using image processing of the top surface.

\subsection{Experimental details}

The experiments have been performed on an ORION-3015 $\mathrm{CO}_{2}$ laser cutting machine using nitrogen as an assistant gas for cleaning the extra material after machining (flushing). ORION-3015 is a carbon dioxide $\left(\mathrm{CO}_{2}\right)$ laser cutting machine set-up having the latest design to provide an intelligent and cost-effective solution for laser processing needs and a Fanuc CNC control that features a 9.5" colour screen. CADMAN-L 3D software is used for controlling

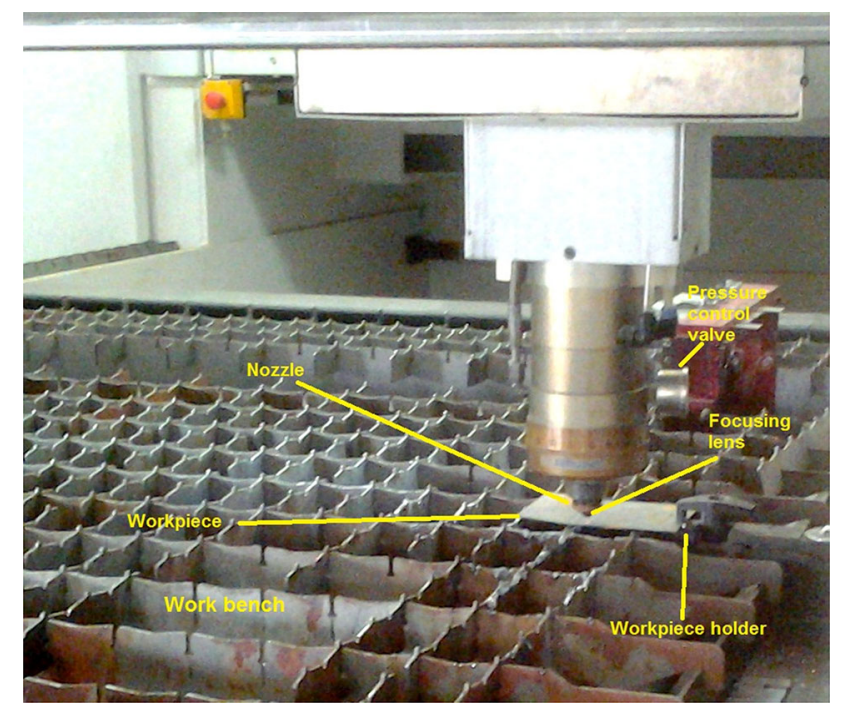

Figure 4. Workpiece set-up for laser drilling. laser processing set-up. Figure 4 shows the workpiece and machine set-up.

The work materials such as Ti6Al4V of thickness $2 \mathrm{~mm}$ are exposed to a focused stationary laser beam of spot size $1.5 \mathrm{~mm}$ with coaxial $\mathrm{CO}_{2}$ gas jet. As the temperature increases, melting of work materials occurs, leading to depression at the centre. The removal of the molten metal has been carried out using $\mathrm{N}_{2}$ as an assistant gas with flushing pressures ranging between 34 and $40 \mathrm{~Pa}$. The workpieces used for the experimental studies are made of a titanium alloy (Ti6Al4V). The material Ti6Al4V is originally in the form of rectangular plate of size $150 \mathrm{~mm} \times 150 \mathrm{~mm}$ and of thickness $2 \mathrm{~mm}$. The workpiece is cut into a square plate of dimension $50 \mathrm{~mm} \times 50 \mathrm{~mm}$ and of thickness $2 \mathrm{~mm}$ (figure 5). The material is procured from Manohar Metal Supply Corporation, Mumbai, India.

A scanning electron microscope (SEM) (Model JEOL JSM-6048LV) having magnification of $8-50,000 \times$ has been used for scanning electron microscopy with energydispersive spectroscopy (SEM-EDS). EDS has been performed to confirm the constituents present in the work material. The image of the sample at 200 microns $(\mu \mathrm{m})$ under a magnification of $500 \times$ from the SEM is obtained and analysis is carried out by energy-dispersive X-ray spectroscopy [34-36]. The SEM-EDS analysis shows that the content of titanium (Ti) is at the peak (figure 6) and the other constituents present in the work sample are vanadium (V) and aluminium (Al). The workpiece possesses $\mathrm{Ti}$ of $92 \%$

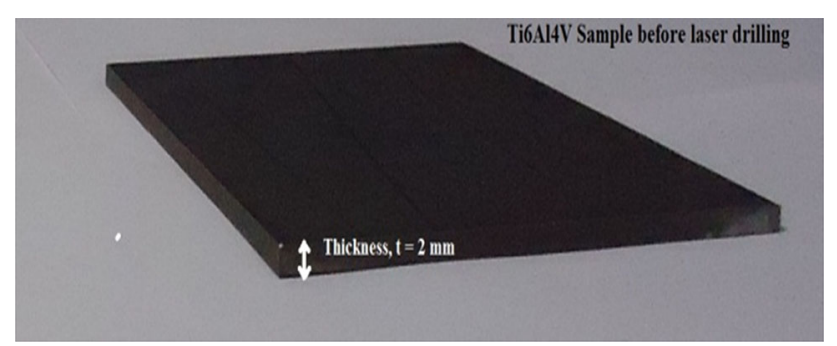

Figure 5. The workpieces before machining.

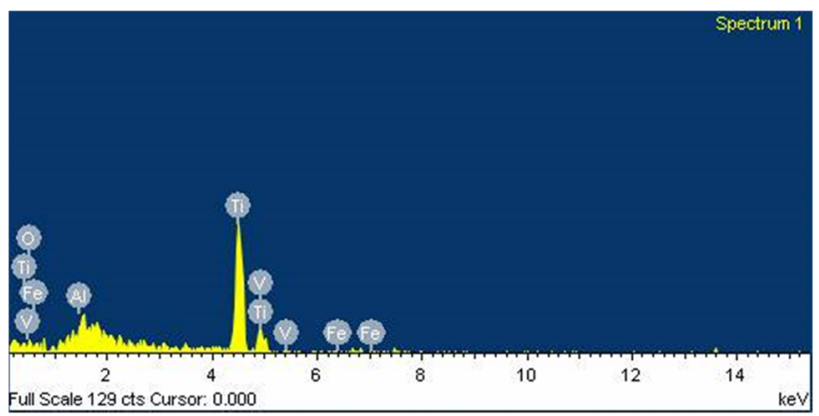

Figure 6. SEM-EDS image of Ti6Al4V. 
Table 2. Control parameters and their levels.

\begin{tabular}{lccrrrr}
\hline & & & & \multicolumn{2}{c}{ Levels } \\
\cline { 3 - 7 } S1. no. & Process parameters & Symbols & Unit & Low & Middle & High \\
\hline 1 & Flushing pressure & $F$ & $\mathrm{~Pa}$ & 34 & 37 \\
2 & Laser power & $L$ & $\mathrm{~W}$ & 2000 & 2250 & 2500 \\
3 & Pulse frequency & $P$ & $\mathrm{~Hz}$ & 1600 & 1800 \\
\hline
\end{tabular}

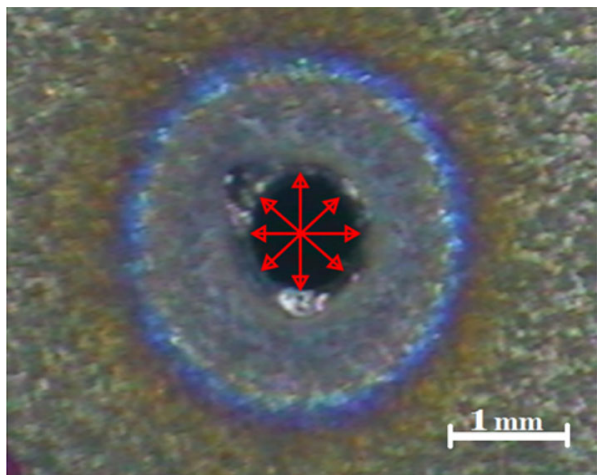

Figure 7. Measurement of hole size in laser drilling.

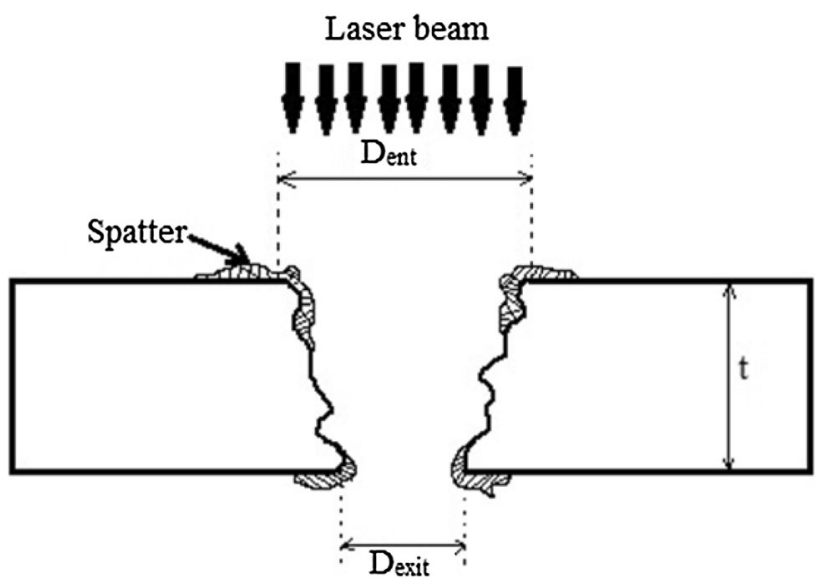

Figure 8. Taper formation on workpiece after laser drilling. atomic weight, $\mathrm{V}$ of $5.35 \%$ atomic weight and $\mathrm{Al}$ of $2.56 \%$ atomic weight. These results confirm that the work sample material is Ti6Al4V and can be used for further analysis.

Taguchi method has been employed to understand the effect of control parameters on various laser drilling performance characteristics with less number of experimental runs. The control parameters are selected through an exhaustive literature survey $[5,6,37,38]$. The control parameters considered are flushing pressure $(F)$ of the assistant gas, laser power $(L)$ and pulse frequency $(P)$, each at three levels. Table 2 lists out process parameters with their designated levels.

The process performance characteristics (responses) considered are taper of the drilled hole, spatter area and HAZ. For laser drilling process, it is necessary to find out average size of the laser drilled hole (figure 7). The images of the laser-drilled holes are obtained using an optical microscope (a RADIAL INSTRUMENT with Samsung camera set-up, 30× magnification). Using image processing toolbox in MATLAB 15a, hole size is measured. The average hole size is found to be $\approx 1.2225 \mathrm{~mm}$ (table 4 ).

The laser cutting process generally produces tapered shape due to the divergence of laser beam [39]. The effect of thickness of the workpiece, focal setting and power intensity significantly influences taper of the hole [40]. Taper is calculated using Eq. (12) where $D_{\text {ent }}$ and $D_{\text {exit }}$ are the diameters at entry and exit of the hole, respectively $[1,6]$. In the present study, it is observed that diameter at entry $\left(D_{\text {ent }}\right)$ is invariably greater than diameter at exit ( $D_{\text {exit }}$ ) (figure 8).

Table 3. Experimental runs and performance characteristics during laser drilling.

\begin{tabular}{|c|c|c|c|c|c|c|}
\hline \multirow[b]{2}{*}{ Experimental run } & \multicolumn{3}{|c|}{ Process parameters } & \multicolumn{3}{|c|}{ Performance characteristics } \\
\hline & Flushing pressure $(\mathrm{Pa})$ & Laser power $(\mathrm{W})$ & Pulse frequency $(\mathrm{Hz})$ & Taper & Spatter area $\left(\mathrm{mm}^{2}\right)$ & $\mathrm{HAZ}(\mathrm{mm})$ \\
\hline 1 & 34 & 2000 & 1600 & 0.1077 & 2.8826 & 0.4826 \\
\hline 2 & 34 & 2250 & 1800 & 0.0722 & 5.5217 & 0.6731 \\
\hline 3 & 34 & 2500 & 2000 & 0.0421 & 10.0175 & 0.9163 \\
\hline 4 & 37 & 2000 & 1800 & 0.1227 & 3.4438 & 0.6718 \\
\hline 5 & 37 & 2250 & 2000 & 0.0945 & 4.5613 & 0.5139 \\
\hline 6 & 37 & 2500 & 1600 & 0.0404 & 6.5964 & 0.7969 \\
\hline 7 & 40 & 2000 & 2000 & 0.0883 & 4.4011 & 0.4948 \\
\hline 8 & 40 & 2250 & 1600 & 0.0505 & 6.3280 & 0.4733 \\
\hline 9 & 40 & 2500 & 1800 & 0.0411 & 9.2811 & 0.9322 \\
\hline
\end{tabular}




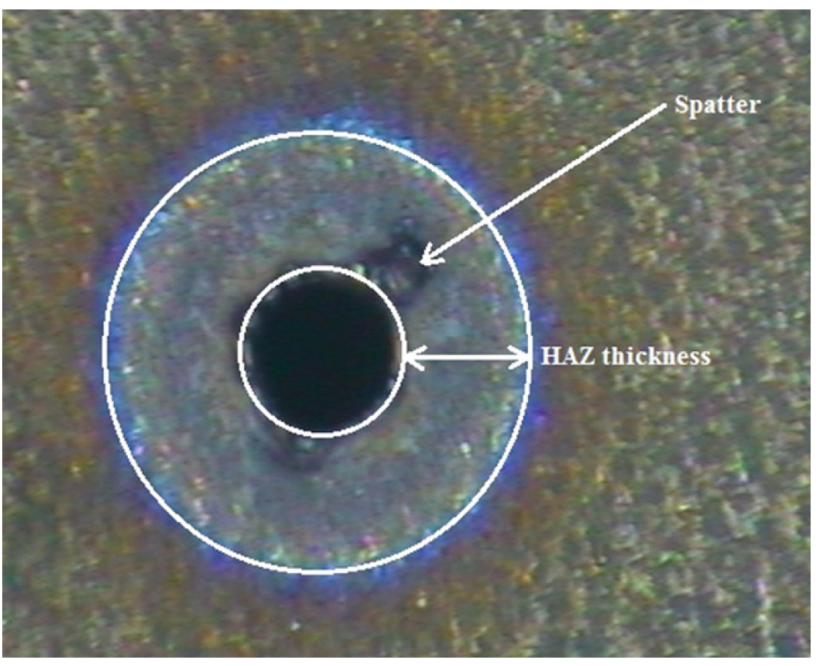

Figure 9. HAZ thickness after laser drilling.

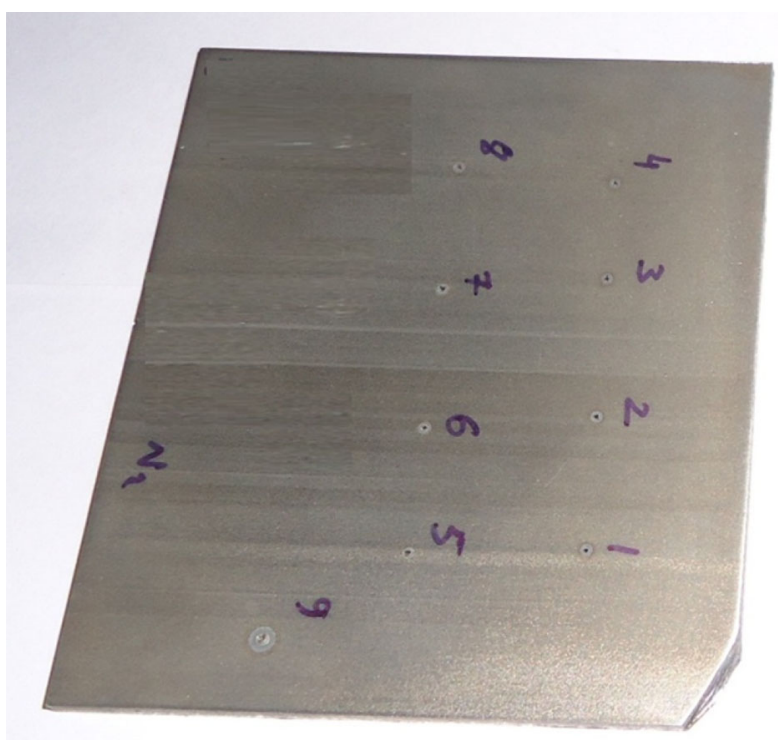

Figure 10. Workpiece after laser drilling.

$$
\text { taper }=\frac{D_{\mathrm{ent}}-D_{\mathrm{exit}}}{2 t} .
$$

Spatter is one of the natural defects that occur during laser drilling. It occurs due to the incomplete flushing of the molten material. The remaining material solidifies and adheres around the periphery of the hole [5]. In the present investigation, the spatter formation occurs on the surface of the holes to a greater extent and spatter is consistently more in case of thin workpieces. The extent of spatter formed on Ti6Al4V materials is significantly different (figure 8). The spatter area is measured using the optical microscope (the RADIAL INSTRUMENT with Samsung camera set-up, $30 \times$ magnification). Images of the hole so acquired are

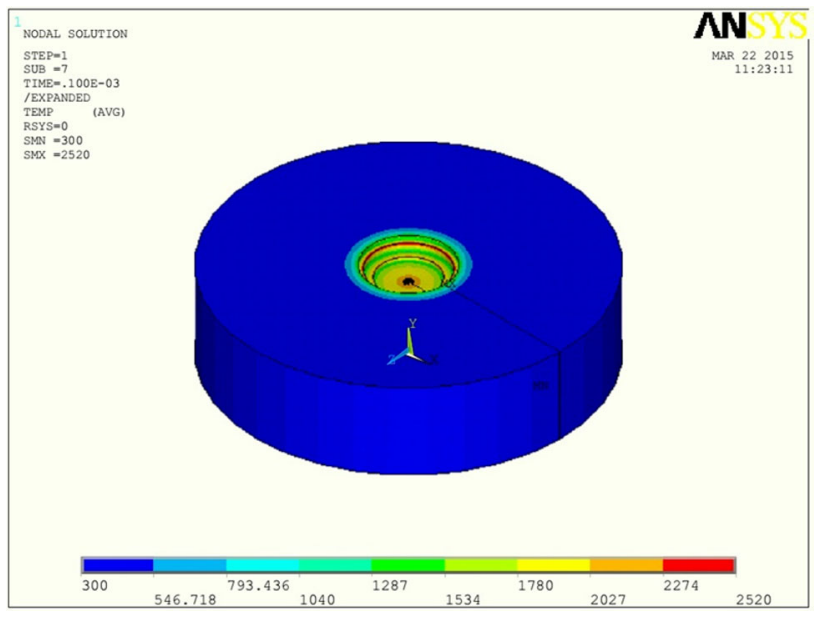

Figure 11. Three-dimensional view of the numerical model.

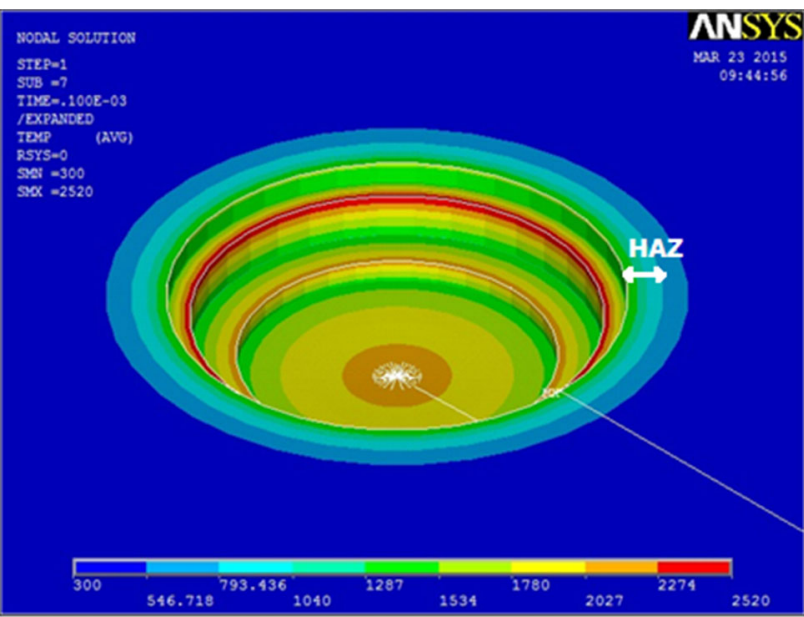

Figure 12. View of the HAZ near the hole profile developed after FE analysis.

used in the image processing toolbox of MATLAB 15a to measure the spatter area (table 3 ).

As laser machining is a thermal process; huge amount of energy is conducted into the workpiece, leading to change in microstructure, material properties and phase composition such as changes in grain size and formation of carbide near the HAZ [41]. The narrow zone formed exactly adjacent to the laser

Table 4. Comparison of numerical and experimental results for hole size.

\begin{tabular}{lccc}
\hline & \multicolumn{2}{c}{ Average hole size $(\mathrm{mm})$} & \\
\cline { 2 - 3 } Power $(\mathrm{W})$ & Numerical & Experimental & Relative error $(\%)$ \\
\hline 2000 & 1.141 & 1.1019 & 3.5484 \\
2250 & 1.172 & 1.2246 & 4.2953 \\
2500 & 1.212 & 1.3412 & 9.6332 \\
\multicolumn{2}{l}{ Mean relative error } & & 5.8256 \\
\hline
\end{tabular}


Table 5. Comparison of numerical and experimental results on HAZ.

\begin{tabular}{lccc}
\hline & \multicolumn{2}{c}{ HAZ thickness $(\mathrm{mm})$} & \\
\cline { 2 - 3 } Power $(\mathrm{W})$ & Numerical & Experimental & Relative error $(\%)$ \\
\hline 2000 & 0.74 & 0.672 & 8.974 \\
2250 & 0.76 & 0.673 & 11.434 \\
2500 & 0.89 & 0.916 & 2.955 \\
Mean relative error & & 7.788 \\
\hline
\end{tabular}

Table 6. Comparison of numerical and experimental results for taper.

\begin{tabular}{lccc}
\hline & \multicolumn{2}{c}{ Taper } & \\
\cline { 2 - 3 } Power $(W)$ & Numerical & Experimental & Relative error (\%) \\
\hline 2000 & 0.1077 & 0.115 & 6.809 \\
2250 & 0.0722 & 0.08 & 10.803 \\
2500 & 0.0421 & 0.046 & 9.264 \\
Mean relative error & & 8.959 \\
\hline
\end{tabular}

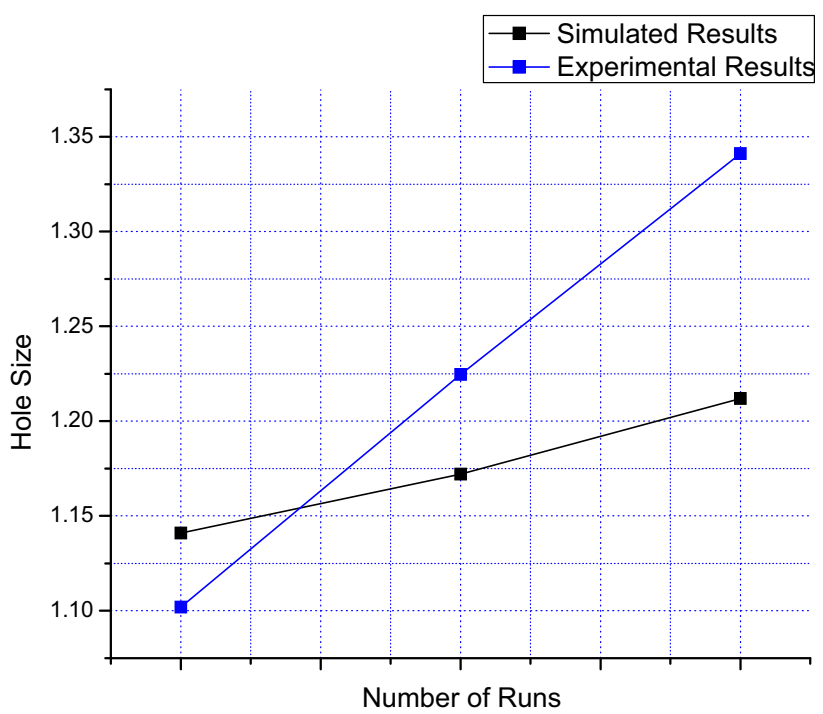

Figure 13. Comparison of numerical and experimental results for average hole size.

drilled holes is known as HAZ (figure 9). The samples are taken under the optical microscope to obtain images of the laser-drilled hole to measure the HAZ as shown in figure 9 [42]. The HAZ thickness is measured using Eq. (13) [43]:

$$
H A Z \text { thickness }=\frac{H A Z \text { diameter }- \text { drilled hole diameter }}{2} .
$$

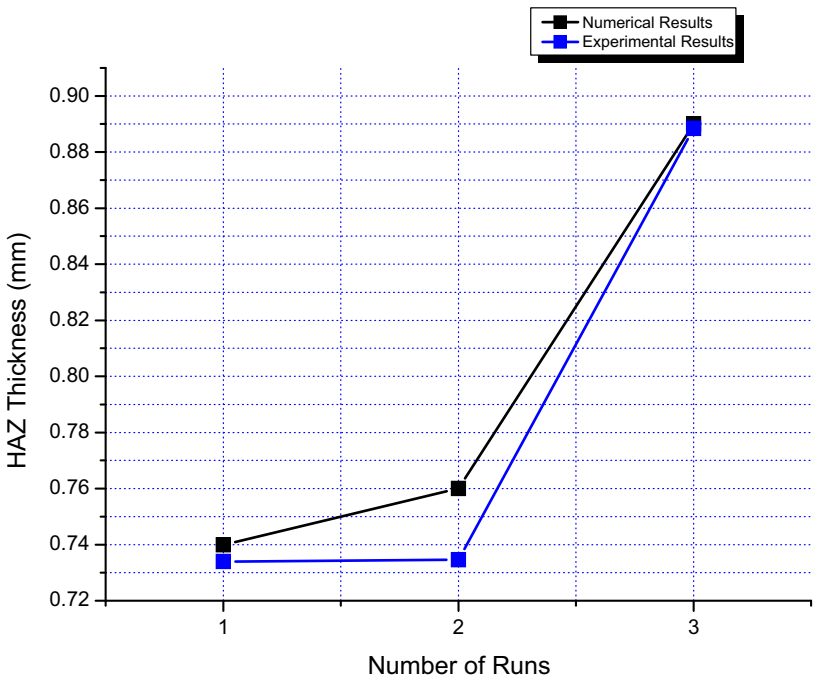

Figure 14. Comparison of numerical and experimental results for HAZ.

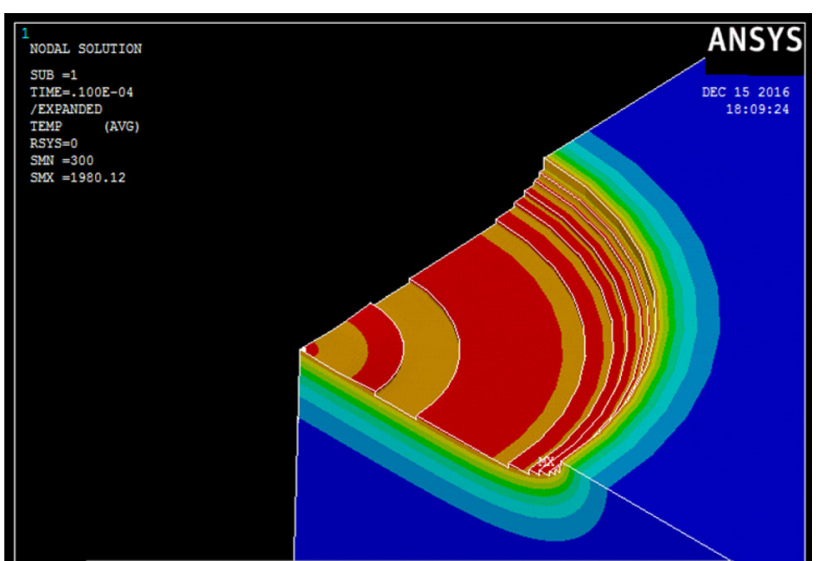

Figure 15. Measurement of taper at $2500 \mathrm{~W}$ power.

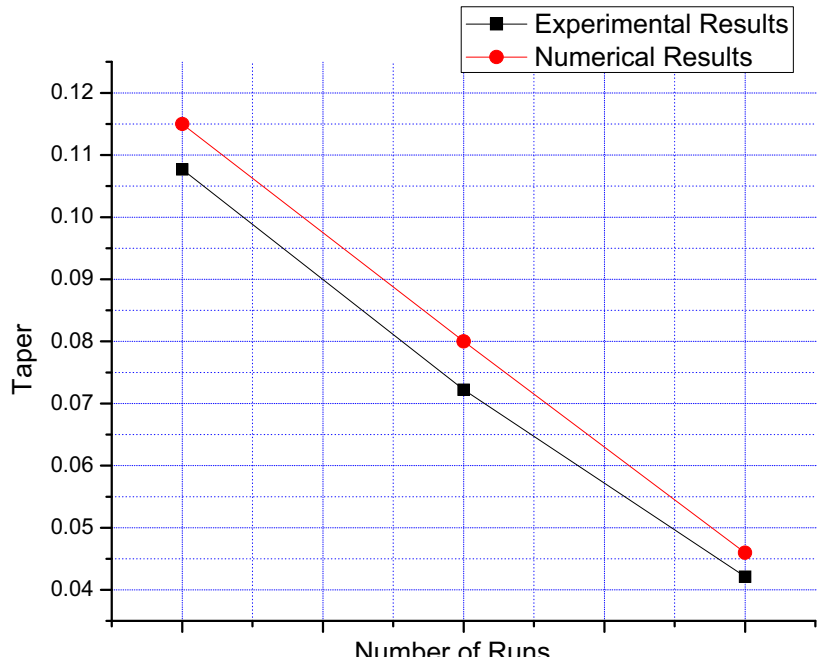

Figure 16. Comparison of numerical and experimental results for taper. 
Table 7. ANOVA for taper of kerf.

\begin{tabular}{lcccrrr}
\hline Source & DF & Seq SS & Adj SS & Adj MS & $F$ & Contribution (\%) \\
\hline$F$ & 2 & 11.28 & 11.28 & 5.64 & 2.94 & 9.452 \\
$L$ & 2 & 100.227 & 100.227 & 50.113 & 1.997 & 1.04 \\
$P$ & 2 & 3.995 & 3.995 & 1.921 & 3.347 & 3.219 \\
Residual error & 2 & 3.842 & 3.842 & & \\
Total & 8 & 119.343 & & & \\
\hline
\end{tabular}

Table 8. ANOVA for HAZ.

\begin{tabular}{lccccrr}
\hline Source & DF & Seq SS & Adj SS & Adj MS & $F$ & Contribution $(\%)$ \\
\hline$F$ & 2 & 1.3059 & 1.3059 & 0.653 & 1.92 & 2.846 \\
$L$ & 2 & 34.536 & 34.536 & 17.268 & 50.72 & 75.255 \\
$P$ & 2 & 9.3689 & 9.3689 & 4.6844 & 13.76 & 20.415 \\
Residual error & 2 & 0.6809 & 0.6809 & 0.3405 & & 1.484 \\
Total & 8 & 45.8917 & & & \\
\hline
\end{tabular}

Table 9. ANOVA for spatter area.

\begin{tabular}{|c|c|c|c|c|c|c|}
\hline Source & $\mathrm{DF}$ & Seq SS & Adj SS & Adj MS & $F$ & Contribution $(\%)$ \\
\hline$F$ & 2 & 10.518 & 10.518 & 5.259 & 2.47 & 9.911 \\
\hline$L$ & 2 & 87.762 & 87.762 & 43.881 & 20.61 & 82.698 \\
\hline$P$ & 2 & 3.584 & 3.584 & 1.792 & 0.84 & 3.377 \\
\hline Residual error & 2 & 4.259 & 4.259 & 2.129 & & 4.013 \\
\hline Total & 8 & 106.124 & & & & \\
\hline
\end{tabular}

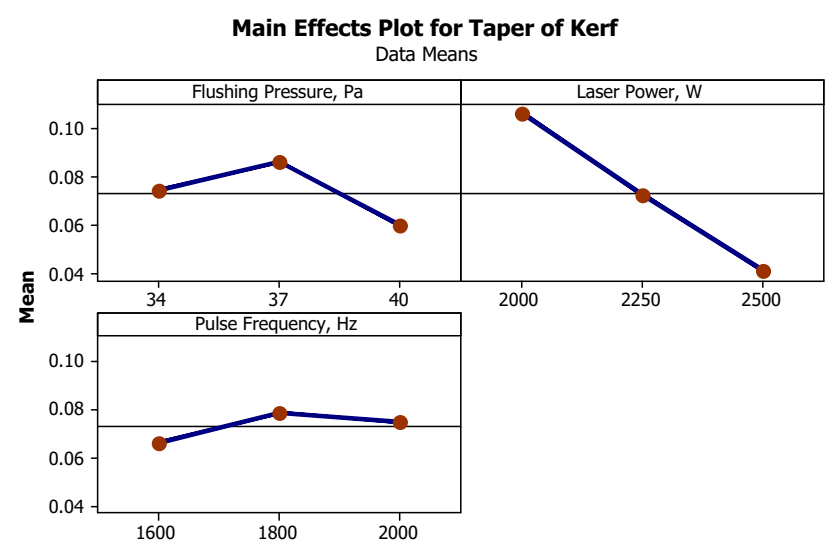

Figure 17. Mean effect plot for taper.

The performance characteristics (responses) of laser drilling process such as taper of kerf, spatter area and HAZ are summarized in table 3 . The laser-drilled samples are shown in figure 10 .

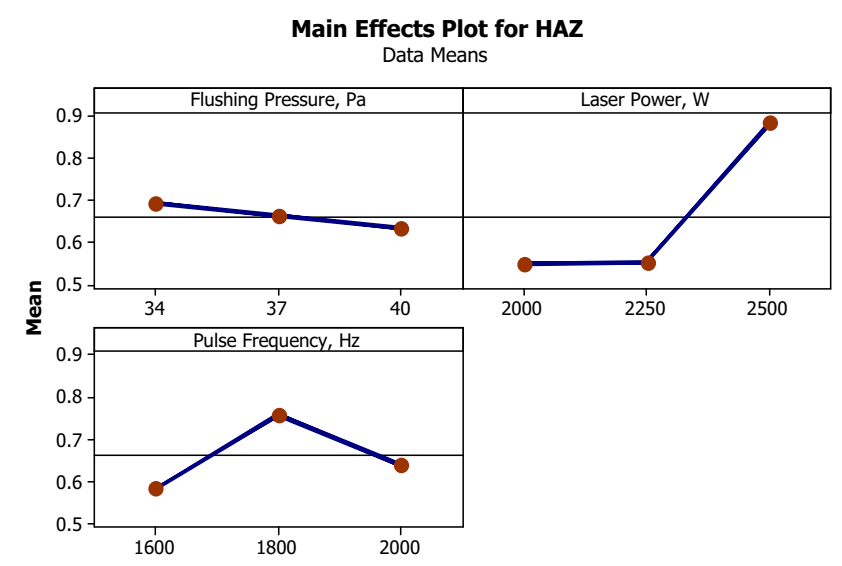

Figure 18. Mean effect plot for HAZ.

\section{Result and discussion}

To analyse the effect of process parameters during laser drilling of Ti6Al4V , the 2D plane in numerical model is converted into a $3 \mathrm{D}$ model (figure 11 ) by rotating the $2 \mathrm{D}$ 


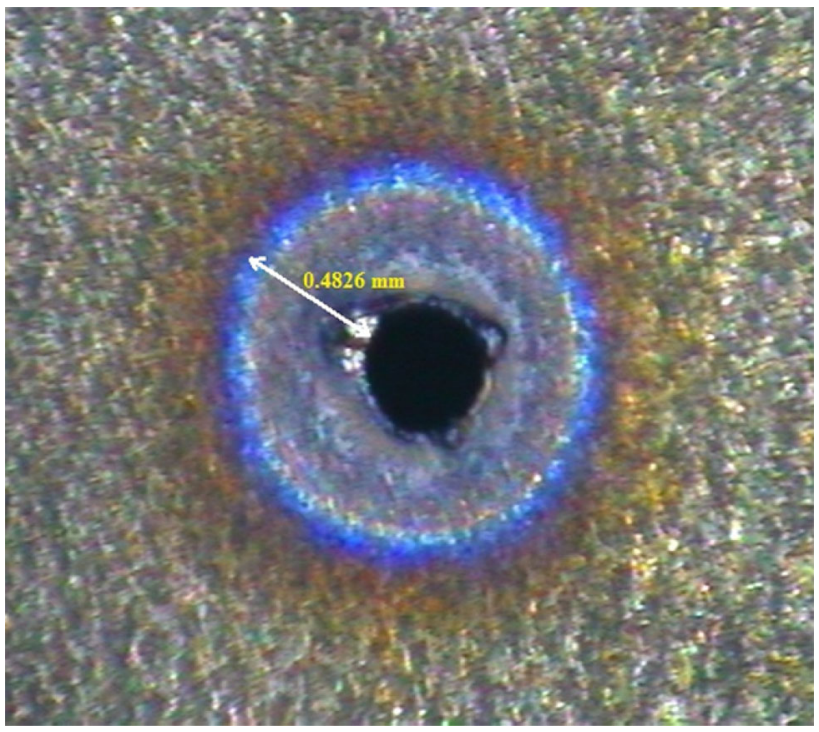

Figure 19. HAZ (thickness) at $45 \times$ magnification and at parametric setting of $34 \mathrm{~Pa}$ flushing pressure, $2000 \mathrm{~W}$ of laser power and pulse frequency of $1600 \mathrm{~Hz}$.

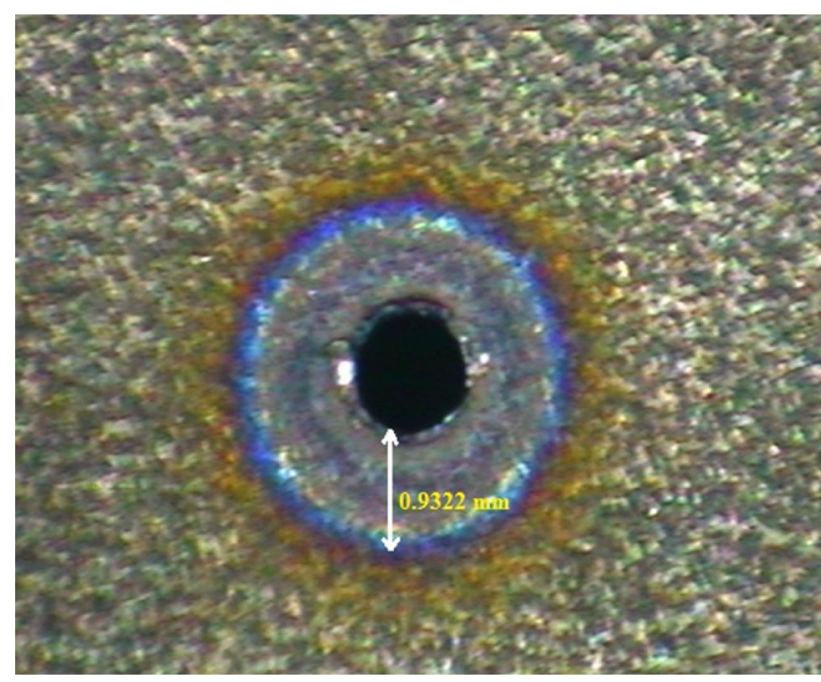

Figure 20. HAZ at $30 \times$ magnification and at parametric setting of $40 \mathrm{~Pa}$ flushing pressure, $2500 \mathrm{~W}$ of laser power and pulse frequency of $1800 \mathrm{~Hz}$.

plane along $y$-axis. The average hole size, HAZ and taper obtained from the numerical model are shown in figures 12 and 15 and enlisted in tables 4, 5 and 6, respectively. To check the adequacy of the proposed model, experiments have been conducted at $1 \mathrm{~Hz}$ pulse frequency and power input ranging from 2000 to $2500 \mathrm{~W}$. The results obtained from the numerical model and experimental investigation are compared and plotted in the graphs (figures 13-16).

The numerical and experimental results for average hole size are found to be quite close (figure 13), having a mean relative error of $5.8256 \%$ (table 4 ).

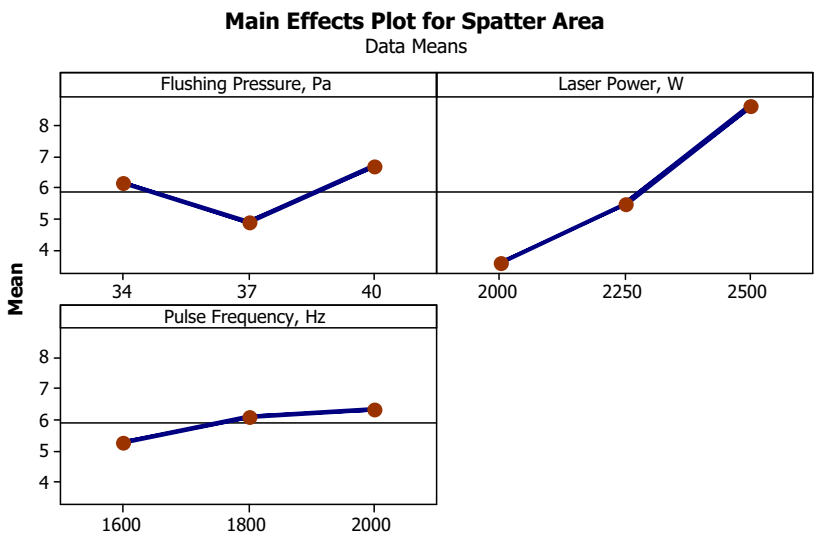

Figure 21. Mean effect plot for spatter area.

The numerical and experimental results obtained for HAZ are found to be quite close, having a mean relative error of $7.788 \%$ (table 5 and figure 14).

In order to check the validity of the numerical model for taper formation during laser drilling process, experiments have been conducted with the identical theoretical condition at $1-\mathrm{Hz}$ pulse frequency. Figure 15 shows the formation of taper in the hole during laser drilling process. The image is exported to MATLAB 15a for the analysis. Numerical analyses have been performed for different laser powers ranging between 2000 and $2500 \mathrm{~W}$ and $1 \mathrm{~Hz}$ of pulse frequency. The obtained results are enlisted in table 6 . The relative error within $10 \%$ (table 6) shows the adequacy of the numerical model. The numerical and experimental results are depicted in figure 16. Further, the proposed model is compared to the results of numerical model proposed by Mishra and Yadava [43]. The proposed model shows a similar trend as taper decreases with increasing laser power.

To know the statistical significance of the control parameters (flushing pressure, laser power and pulse frequency), the analysis of variance (ANOVA) is performed on the drilling performance characteristics such as taper of the kerf, HAZ and spatter area as shown in tables 7, 8 and 9 , respectively. To analyse the parametric effect on the process responses during laser drilling operation, ANOVA for each drilling response has been performed. The coefficients of determination $\left(R^{2}\right)$ for taper, HAZ thickness and spatter area are $96.80 \%, 98.50 \%$ and $96 \%$, respectively.

Table 7 shows that laser power has higher percentage of contribution (83.982\%) on formation of taper during laser drilling of Ti6Al4V. The main effect plot shows that taper of kerf decreases with increases in laser power (figure 17). Increase in laser power leads to high energy generation and melting and vaporization occurs properly. Further, less heat is conducted through the workpiece as titanium alloys are low-conductivity materials. The optimal parameter setting for achieving minimum taper is flushing pressure of $40 \mathrm{~Pa}$, laser power of $2500 \mathrm{~W}$ and frequency of $1600 \mathrm{~Hz}$. 
Table 10. Calculated desirability values, overall desirability values and $\mathrm{S} / \mathrm{N}$ ratios.

\begin{tabular}{lccccc}
\hline & \multicolumn{3}{c}{ Desirability values } & & \\
\cline { 2 - 5 } Experimental run & Taper of kerf & Spatter area & HAZ & Overall desirability values & S/N ratio \\
\hline 1 & 0.573 & 0.900 & 0.892 & 0.771873 & -2.24908 \\
2 & 0.745 & 0.752 & 0.726 & 0.741027 & -2.60332 \\
3 & 0.892 & 0.500 & 0.514 & 0.611905 & -4.26633 \\
4 & 0.500 & 0.869 & 0.727 & 0.680916 & -3.33814 \\
5 & 0.637 & 0.806 & 0.865 & 0.762825 & -2.35150 \\
6 & 0.900 & 0.692 & 0.618 & 0.727312 & -2.13038 \\
7 & 0.667 & 0.815 & 0.881 & 0.814985 & -1.77700 \\
8 & 0.851 & 0.707 & 0.900 & 0.623732 & -4.10005 \\
9 & 0.897 & 0.541 & 0.500 & &
\end{tabular}

Table 11. ANOVA of overall desirability.

\begin{tabular}{lccccrr}
\hline Source & DF & Seq SS & Adj SS & Adj MS & $F$ & Contribution (\%) \\
\hline$F$ & 2 & 0.2084 & 0.2084 & 0.1042 & 0.34 & 5.387 \\
$L$ & 2 & 3.5545 & 3.5545 & 1.7773 & 5.87 & 2.95 \\
$P$ & 2 & 1.7847 & 1.7847 & 0.8923 & 0.3027 & \\
Residual error & 2 & 0.6055 & 0.6055 & & \\
Total & 8 & 6.1531 & & & \\
\hline
\end{tabular}

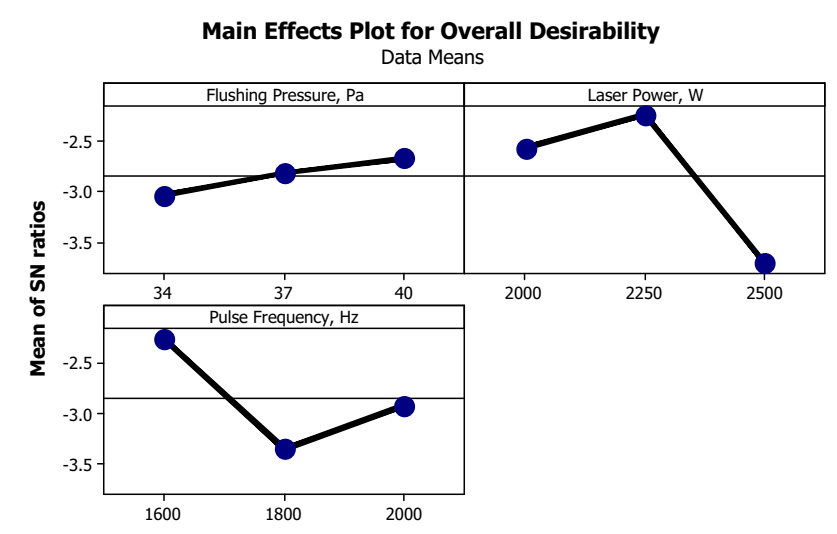

Signal-to-noise: Larger is better

Figure 22. Main effect plot for $\mathrm{S} / \mathrm{N}$ ratio of overall desirability values.

ANOVA for HAZ shows that laser power contributes $75.255 \%$ on development of HAZ in laser drilling of Ti6Al4V (table 8). The main effect plot shows that HAZ decreases with increases in laser power (figure 18). The optimal parameter setting for achieving minimum HAZ is flushing pressure of $40 \mathrm{~Pa}$, laser power of $2000 \mathrm{~W}$ and frequency of $1600 \mathrm{~Hz}$. Figures 19 and 20 show that the HAZ increases with pulse frequency.

ANOVA for spatter area shows that laser power has higher percentage of contribution (82.698\%) on spatter area during laser drilling of Ti6Al4V (table 9). The main effect plot shows that spatter area increases monotonously with

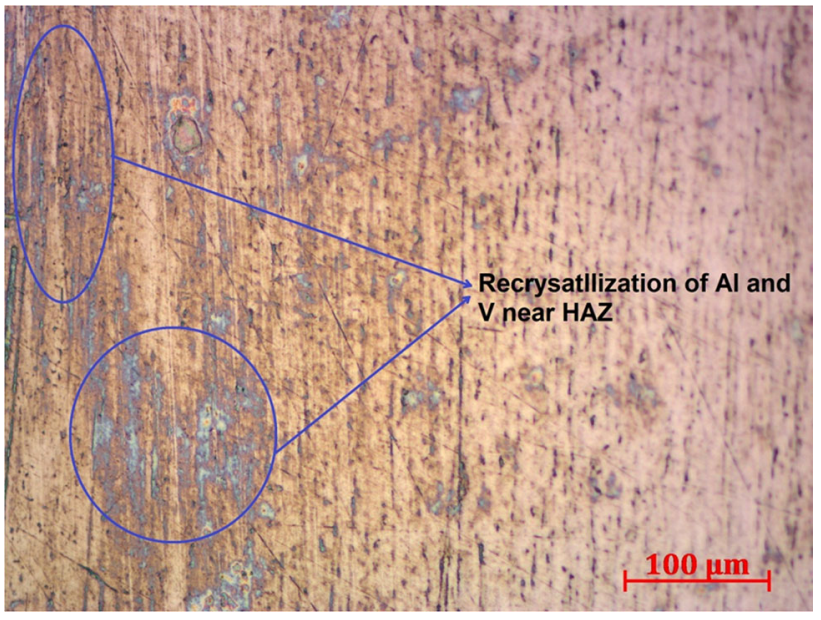

Figure 23. Micro-surface texture of the laser holes at flushing pressure of $37 \mathrm{~Pa}$, laser power of $2000 \mathrm{~W}$ and $2000 \mathrm{~Hz}$ pulse frequency.

increases in laser power (figure 21). The optimal parameter setting for achieving minimum spatter area is flushing pressure of $37 \mathrm{~Pa}$, laser power of $2000 \mathrm{~W}$ and frequency of $1600 \mathrm{~Hz}$.

For obtaining the best parametric condition, simultaneous optimization of taper of kerf, HAZ and spatter area has been performed using DFA. The performance characteristics such as taper of kerf, HAZ and spatter area should be minimized. To attain this condition, performance 
characteristics are converted into individual desirability value $d_{\mathrm{i}}$ using LTB criteria using Eqs. (1)-(3) (table 10). The desirability values are converted into overall desirability value (Eq. (7)) taking desirability index ( $r$ ) equal to 1 and the values are tabulated in table 10 [25].

To optimize performance characteristics such as taper, spatter area and HAZ simultaneously, the characteristics are converted into single-equivalent characteristics (overall desirability value). Obtained overall desirability value is converted to $\mathrm{S} / \mathrm{N}$ ratio (Eq. (9)) taking larger the better criterion. The coefficient of determination $\left(R^{2}\right)$ of $90.20 \%$ shows the adequacy of the overall desirability values. ANOVA (table 11) for overall desirability value shows that laser power contributes largely $(57.768 \%)$ on overall desirability during laser drilling of Ti6Al4V (table 11). The main effect plot shows that overall desirability value increases monotonously with increases in flushing pressure (figure 22). The optimal parameter setting for achieving maximum overall desirability value is flushing pressure of $40 \mathrm{~Pa}$, laser power of $2250 \mathrm{~W}$ and frequency of $1600 \mathrm{~Hz}$.

The optimum parametric setting for overall desirability obtained is flushing pressure of $40 \mathrm{~Pa}$, laser power of $2250 \mathrm{~W}$ and pulse frequency of $1600 \mathrm{~Hz}\left(F_{3} L_{2} P_{1}\right)$. Ten experimental trials have been conducted at optimal setting to confirm the validity of the obtain optimum parametric setting.

The confidence interval is calculated using the following Eq. (12) [44, 45]:

$$
C I=\sqrt{F_{\alpha}\left(l ; f_{e}\right) V_{e}\left[\frac{1}{N_{\mathrm{eff}}}+\frac{1}{R}\right]}
$$

where $F_{\alpha}\left(l ; f_{e}\right)$ is the Fishers value at $\alpha \%$ of significance level, $V_{e}$ is the variance error, $R$ is the total number of replications and $N_{\text {eff }}$ is the effective total number of tests (Eq. (13)) [44, 45]:

$$
N_{\text {eff }}=\frac{N}{1+T_{D O F}}
$$

where $N$ is total number of experimental runs and $T_{\mathrm{DOF}}$ is total degrees of freedom. Therefore, $95 \%$ confidence interval for the optimum setting of the experimental run is $C I= \pm 1.22$.

$$
\begin{array}{r}
(\bar{x}-C I) \leq \mu \leq(\bar{x}+C I) \\
-2.72 \leq \mu \leq-0.264
\end{array}
$$

where $\bar{x}$ is sample mean and $\mu$ is expected mean.

Equation (14) is used to predict the $S / N$ ratio at optimum setting [44, 45]:

$$
S / N=\bar{Y}+\left(\overline{F_{3}}-\bar{Y}\right)+\left(\overline{L_{2}}-\bar{Y}\right)+\left(\overline{P_{1}}-\bar{Y}\right)
$$

where $\bar{Y}$ is the average $\mathrm{S} / \mathrm{N}$ ratio of all the experimental runs, $\overline{F_{3}}$ is the average $\mathrm{S} / \mathrm{N}$ ratio of the flushing pressure at
$40 \mathrm{~Pa}, \overline{L_{2}}$ is the average $\mathrm{S} / \mathrm{N}$ ratio of the laser power at $2250 \mathrm{~W}$ and $\overline{P_{1}}$ is the average $\mathrm{S} / \mathrm{N}$ ratio of the pulse frequency at $1600 \mathrm{~Hz}$. The calculated value of $S / N$ ratio is -1.492 . Since the predicted $S / N$ ratio lies within the $95 \%$ confidence interval, the Taguchi method suggesting optimal setting is confirmed.

The micro-structural analysis for surface texture of the laser-machined surface has been performed using an optical microscope (Zoom Lenses of Carl Zesis, 100× magnification) at flushing pressure of $37 \mathrm{~Pa}$, laser power of $2000 \mathrm{~W}$ and $2000 \mathrm{~Hz}$ pulse frequency. From figure 23, it is observed that elements present in the titanium (Ti6Al4V) alloy such as $\mathrm{Al}$ and $\mathrm{V}$ are melted and recrystallized near the HAZ (near laser-drilled hole). The components of the alloy are melted at $2000 \mathrm{~W}$ and may be recrystallized due to flushing.

\section{Conclusions}

In the present study, $\mathrm{CO}_{2}$ laser drilling of Ti6Al4V has been studied to identify the effect of laser process parameters (i.e., flushing pressure, laser power and pulse frequency) on performance characteristics such as taper of kerf, spatter area and HAZ. In the present study, a numerical model is proposed for laser drilling to predict the quality characteristics such as hole size, HAZ and taper. The results obtained from the numerical model show good agreement with the experimental results as relative error is within $10 \%$. It is observed that laser power is the most significant process parameter during laser drilling of Ti6Al4V for the quality characteristics such as taper of kerf, HAZ and spatter area having percentage contribution of $83.982 \%, 75.255 \%$ and $82.698 \%$, respectively. It is also observed that spatter area and HAZ increase with increase in laser power whereas taper of kerf reduces with increase in laser power. Multiresponse optimization is carried out for identifying optimum parametric setting using DFA considering performance characteristics such as taper of kerf, HAZ and spatter area. It is observed that laser power and pulse frequency are the significant parameters for multiple responses.

\section{References}

[1] Yeo C Y, Tam S C, Jana S and Lau M W 1994 A technical review of the laser drilling of aerospace materials. J. Mater. Process. Technol. 42(1): 15-49

[2] Tansel I, Rodriguez O, Trujillo M, Paz E and Li W 1998 Micro-end-milling-I. Wear and breakage. Int. J. Mach. Tools Manuf. 38(12): 1419-1436

[3] Bellows G and Kohls J 1982 Drilling without drills. American Mach. 126(3): 173-188 
[4] Chryssolouris G, Bredt J, Kordas S and Wilson E 1988 Theoretical aspects of a laser machine tool. J. Manuf. Sci. Eng. 110(1): 65-70

[5] Low D K Y, Li L and Byrd P J 2000 The effects of process parameters on spatter deposition in laser percussion drilling. Opt. Laser Technol. 32(5): 347-354

[6] Ghoreishi M, Low D K Y and Li L 2000 Comparative statistical analysis of hole taper and circularity in laser percussion drilling. Int. J. Mach. Tools Manuf. 42(9): 985-995

[7] Brajdic M, Walther K and Eppelt U 2008 Analysis of laser drilled deep holes in stainless steel by superposed pulsed $\mathrm{Nd}$ : YAG laser radiation. Opt. Lasers Eng. 46(9): 648-655

[8] Nagesh S, Narasimha Murthy H N, Krishna M and Basavaraj $\mathrm{H} 2013$ Parametric study of $\mathrm{CO}_{2}$ laser drilling of carbon nano-powder/vinylester/glass nano-composites using design of experiments and grey relational analysis. Opt. Laser Technol. 48: 480-488

[9] Shelton J A and Shin Y C 2010 Comparative evaluation of laser-assisted micro-milling for AISI 316, AISI 422, TI-6AL$4 \mathrm{~V}$ and Inconel 718 in a side-cutting configuration. J. MicroMech. Micro-Eng. doi:10.1088/0960-1317/20/7/075012

[10] Yan Y, Ji L, Bao Y and Jiang Y 2012 An experimental and numerical study on laser percussion drilling of thick-section alumina. J. Mater. Process. Technol. 212(6): 1257-1270

[11] El-Taweel T A, Abdel-Maaboud A M, Azzam B S and Mohammad A E 2009 Parametric studies on the $\mathrm{CO}_{2}$ laser cutting of Kevlar-49 composite. Int. J. Adv. Manuf. Technol. 40(9-10): 907-917

[12] Shuja S Z and Yilbas B S 2014 Flow and heat transfer characteristics of assisting gas impinging onto an alumina coated hole in relation to laser drilling. Opt. Laser Technol. 59: $123-130$

[13] Rozzi J C, Pfefferkorn F E, Incropera F P and Shin Y C 2000 Transient, three-dimensional heat transfer model for the laser assisted machining of silicon nitride: I. Comparison of predictions with measured surface temperature histories. Int. J. Heat Mass Transfer 43(8): 1409-1424

[14] Rozzi J C, Pfefferkorn F E, Shin Y C and Incropera F P 2000 Experimental evaluation of the laser assisted machining of silicon nitride ceramics. J. Manuf. Sci. Eng. 122(4): 666-670

[15] Yan Y, Li L, Sezer K, Whitehead D, Ji L, Bao Y and Jiang Y 2011 Experimental and theoretical investigation of fibre laser crack-free cutting of thick-section alumina. Int. J. Mach. Tools Manuf. 51(12): 859-870

[16] Tsai C H and Chen H W 2003 Laser cutting of thick ceramic substrates by controlled fracture technique. J. Mater. Process. Technol. 136(1): 166-173

[17] Bharatish A, Murthy H N, Anand B, Madhusoodana C D, Praveena G S and Krishna M 2013 Characterization of hole circularity and heat affected zone in pulsed $\mathrm{CO}_{2}$ laser drilling of alumina ceramics. Opt. Laser Technol. 53: 22-32

[18] Dell'Erba M, Galantucci L M and Miglietta S 1992 An experimental study on laser drilling and cutting of composite materials for the aerospace industry using excimer and $\mathrm{CO}_{2}$ sources. Compos. Manuf. 3(1): 14-19

[19] Aoyama E, Inoue H, Hirogaki T, Nobe H, Kitahara Y and Katayama T 1995 Study on small diameter drilling in GFRP. Compos. Struct. 32(1): 567-573

[20] Hirogaki T, Aoyama E, Inoue H, Ogawa K, Maeda S and Katayama T 2001 Laser drilling of blind via holes in aramid and glass/epoxy composites for multi-layer printed wiring boards. Composites Part A: Appl. Sci. Manuf. 32(7): 963-968

[21] Veniali F, Di Ilio A and Tagliaferri V 1995 An experimental study of the drilling of aramid composites. J Energy Resour. Technol. 117(4): 271-278

[22] Derringer G 1980 Simultaneous optimization of several response variables. J. Qual. Technol. 12: 214-219

[23] Sait A N, Aravindan S and Haq A N 2009 Optimisation of machining parameters of glass-fibre-reinforced plastic (GFRP) pipes by desirability function analysis using Taguchi technique. Int. J. Adv. Manuf. Tech. 43(5-6): 581-589

[24] Pasandideh S H R and Niaki S T A 2006 Multi-response simulation optimization using genetic algorithm within desirability function framework. Appl. Math. Comput. 175(1): 366-382

[25] Singh A, Datta S, Mahapatra S S, Singha T and Majumdar G 2013 Optimization of bead geometry of submerged arc weld using fuzzy based desirability function approach. J. Intel. Manuf. 24(1): 35-44

[26] Datta S, Bandyopadhyay A and Pal P K 2006 Desirability function approach for solving multi-objective optimization problem in submerged arc welding. J. Manuf. Sci. Prod. 7(2): $127-138$

[27] Jin D and Lin S 2012 Advances in electronic commerce, web application and communication. Wuhan: Springer

[28] Jeong I J and Kim K J 2009 An interactive desirability function method to multiresponse optimization. Eur. J. Oper. Res. 195(2): 412-426

[29] Aggarwal A, Singh H, Kumar P and Singh M 2008 Optimization of multiple quality characteristics for $\mathrm{CNC}$ turning under cryogenic cutting environment using desirability function. J. Mater. Process. Technol. 205(1): 42-50

[30] Kim K J and Lin D K 2000 Simultaneous optimization of mechanical properties of steel by maximizing exponential desirability functions. J. R. Stat. Soc.: Series C (Appl. Stat.) 49(3): 311-325

[31] Nyon K Y, Nyeoh C Y, Mokhtar M and Abdul-Rahman R 2012 Finite element analysis of laser inert gas cutting on Inconel 718. Int. J. Adv. Manuf. Technol. 60(9-12): 995-1007

[32] Chen M F, Hsiao W T, Wang M C, Yang K Y and Chen Y F 2015 A theoretical analysis and experimental verification of a laser drilling process for a ceramic substrate. Int. J. Adv. Manuf. Technol. 81: 1-10

[33] Negarestani R, Sundar M, Sheikh M A, Mativenga P, Li L, Li Z L, Chu P L, Khin C C, Zheng H Y and Lim G C 2010 Numerical simulation of laser machining of carbon-fibrereinforced composites. Proc. Inst. Mech. Engineers Part B: J. Eng. Manuf. 224(7): 1017-1027

[34] Ye H Z and Liu X Y 2005 Microstructure and tensile properties of Ti6Al4V/AM60B magnesium matrix composite. J. Alloys Compd. 402(1): 162-169

[35] Hascalik A and Caydas U 2007 Electrical discharge machining of titanium alloy (Ti-6Al-4V). Appl. Surf. Sci. 253(22): 9007-9016

[36] Kayali Y, Buyuksagis A, Gunes I and Yalcin Y 2013 Investigation of corrosion behaviors at different solutions of boronized AISI 316L stainless steel. Prot. Met. Phys. Chem. Surf. 49(3): 348-358

[37] Reissig L, Volkl R, Mills M J and Glatzel U 2004 Investigation of near surface structure in order to determine 
process-temperatures during different machining processes of Ti6Al4V. Scr. Mater. 50(1): 121-126

[38] Bandyopadhyay S, Gokhale H, Sarin Sundar J K, Sundararajan G and Joshi S V 2005 A statistical approach to determine process parameter impact in Nd: YAG laser drilling of IN718 and Ti-6Al-4V sheets. Opt. Lasers Eng. 43(2): 163-182

[39] Adams Jr. C M and Hardway G 1965 Fundamentals of laser beam machining and drilling. IEEE Trans. Ind. Gen. Appl. IGA-1 (2): 90-96

[40] Yilbas B S 1997 Parametric study to improve laser hole drilling process. J. Mater. Process. Technol. 70(1): 264-273

[41] Prusa J M, Venkitachalam G and Molian P A 1999 Estimation of heat conduction losses in laser cutting. Int. J. Mach. Tools Manuf. 39(3): 431-458
[42] Padhee S, Pani S and Mahapatra S S 2011 A parametric study on laser drilling of $\mathrm{Al} / \mathrm{SiCp}$ metal-matrix composite. Proc. Inst. Mech. Eng. Part B: J. Eng. Manuf. 226(1): 76-91

[43] Mishra S and Yadava V 2013 Prediction of hole characteristics and hole productivity during pulsed Nd: YAG laser beam percussion drilling. Proc. Inst. Mech. Eng. Part B: J. Eng. Manuf. 227(4): 494-507

[44] Singh H and Kumar P 2004 Tool wear optimization in turning operation by Taguchi method. Ind. J. Eng. Mater. Sci. 11(1): 19-24

[45] Haq A N, Marimuthu P and Jeyapaul R 2008 Multi response optimization of machining parameters of drilling $\mathrm{A} 1 / \mathrm{SiC}$ metal matrix composite using grey relational analysis in the Taguchi method. Int. J. Adv. Manuf. Technol. 37(3-4): 250-255 